\title{
EFECTO DE CITOCININAS EN LA PROPAGACIÓN in vitro DE AGAVES MEXICANOS
}

\author{
EFFECT OF CYTOKININS ON THE in vitro PROPAGATION OF MEXICAN AGAVES
}

\author{
Manuel S. Domínguez Rosales ${ }^{1}$, Ángel G. Alpuche Solís ${ }^{2}$, Nora L. Vasco Méndez ${ }^{1}$ y \\ Eugenio Pérez Molphe Balch ${ }^{1 *}$
}

\begin{abstract}
${ }^{1}$ Dpto. de Química, Centro de Ciencias Básicas, Universidad Autónoma de Aguascalientes. Av. Universidad 940. 20100, Aguascalientes, Ags. México. Tel. (52) 449910-8420. ${ }^{2}$ División de Biología Molecular, Instituto Potosino de Investigación Científica y Tecnológica, A. C. Camino a la Presa San José 2055. 78216, San Luis Potosí, S.L.P., México.
\end{abstract}

*Autor para correspondencia (eperezmb@correo.uaa.mx)

\section{RESUMEN}

La falta de sistemas eficientes de propagación es un factor que limita el aprovechamiento racional de varias especies de Agave, que en muchos casos han tenido una reducción peligrosa de sus poblaciones debido a la sobreexplotación de materiales silvestres. En este estudio se desarrollaron protocolos para la propagación in vitro de Agave cupreata, A. difformis, A. karwinskii, A. obscura y A. potatorum. Como explantes se utilizaron tejidos meristemáticos extraídos de plántulas germinadas in vitro. Se logró la formación de brotes múltiples en explantes basales en medio MS adicionado con $30 \mathrm{~g} \mathrm{~L}^{-1}$ de sacarosa, $8 \mathrm{~g} \mathrm{~L}^{-1}$ de agar y varios tratamientos con citocininas [6bencilaminopurina (BA), 6- $\gamma, \gamma$-dimetilalilaminopurina (2iP), cinetina (Cin), tidiazurón (TDZ) y meta-topolina o $\mathbf{N}^{6}$-(metahidroxibencil)adenina (MT)]. Las eficiencias más altas en producción de brotes en $A$. cupreata y A. karwinskii se obtuvieron con 1.5 y $1 \mathrm{mg}$ $\mathrm{L}^{-1}$ de $\mathrm{BA}$, donde se generaron 10.5 y 6.1 brotes por explante, respectivamente. En $A$. difformis y $A$. obscura las mejores respuestas se obtuvieron con $0.2 \mathrm{mg} \mathrm{L}^{-1} \mathrm{TDZ}$ con 8.5 y 11 brotes por explante, respectivamente. En $A$. potatorum la mejor respuesta ocurrió con 3 $\mathrm{mg} \mathrm{L}^{-1} \mathrm{Cin}$, en el que se produjeron 6.9 brotes por explante. El enraizamiento de los brotes generados in vitro se alcanzó en medio MS basal con eficiencias entre 80 y $100 \%$, y la frecuencia de supervivencia de las plantas una vez transferidas a suelo fue de $72 \%$ en promedio.

Palabras clave: Agave spp., citocininas, micropropagación.

\section{SUMMARY}

The lack of efficient propagation systems is one factor limiting the rational use of several species of Agave, which in many cases have had a dangerous reduction of their populations due to the overexploitation of wild materials. In this work in vitro propagation protocols were developed for Agave cupreata, A. difformis, A. karwinskii, $A$. obscura and $A$. potatorum. Meristematic tissues from in vitro germinated seedlings were used as explants. Multiple shoot formation from basal explants was achieved on MS medium supplemented with $30 \mathrm{~g} \mathrm{~L}^{-1}$ sucrose, $8 \mathrm{~g} \mathrm{~L}^{-1}$ agar and various treatments with cytokinins [6-benzylaminopurine (BA), 6- $\gamma, \gamma$-dimethylallylaminopurine (2iP), kinetin (Kin), thidiazuron (TDZ) and meta-topolin or $\mathrm{N}^{6}$ (meta-hydroxybenzyl)adenine (MT)]. The highest shoot production efficiencies for $A$. cupreata and $A$. karwinskii were obtained with 1.5 and $1 \mathrm{mg} \mathrm{L}^{-1} \mathrm{BA}$, which rendered 10.5 and 6.1 shoots per explant, respectively. In $A$. difformis and $A$. obscura the best responses were obtained with $0.2 \mathrm{mg} \mathrm{L}^{-1} \mathrm{TDZ}$, which yielded 8.5 and 11 shoots per explant, respectively. In $A$. potatorum the best response occurred with $3 \mathrm{mg} \mathrm{L}^{-1}$ Kin where 6.9 shoots per explant were produced. Rooting of the in vitro generated shoots was achieved on MS basal media with frequencies ranging from 80 to $100 \%$, and survival of plants transferred to soil was $72 \%$, on the average.

Index words: Agave spp., cytokinins, micropropagation.

\section{INTRODUCCIÓN}

Las especies del género Agave han sido importantes para los pobladores de México desde tiempos remotos y se mantienen como una opción productiva interesante en diversas zonas áridas y semiáridas del país. Esto se debe a la amplia diversidad de usos que tienen estas plantas, ya que son productoras de alimento, de fibras naturales, de materia prima para elaborar bebidas alcohólicas y de materiales para la construcción, y por su importancia reciente como plantas ornamentales (García-Mendoza, 1995). Por ello ha cobrado interés el desarrollo de tecnologías para facilitar su manejo y mejoramiento, como el cultivo y propagación masiva in vitro que permite reproducir clones en tiempos y espacios mínimos. Además, estas técnicas sirven para el estudio y producción in vitro de metabolitos secundarios o el mejoramiento mediante la ingeniería genética.

Existen trabajos acerca del cultivo y propagación in vitro en especies de Agave productoras de fibras, como $A$. fourcroydes (Robert et al., 1987), A. cantala y A. sisalana (Binh et al., 1990; Nikam, 1997; Hazra et al., 2002). También se han estudiado especies que se emplean para producir bebidas fermentadas y licores, como Agave angustifolia (Enríquez-del-Valle et al., 2005), A. tequilana 
(Valenzuela-Sánchez et al., 2006) y A. salmiana (SilosEspino et al., 2007), así como en la micropropagación de agaves amenazados de alto valor ornamental como $\mathrm{A}$. arizonica (Powers y Backhaus, 1989), A. parrasana (Santacruz-Ruvalcaba et al., 1999) y A. victoriae-reginae (Martínez-Palacios et al., 2003).

Tales especies fueron propagadas in vitro a partir del cultivo de meristemos basales o mediante embriogénesis somática u organogénesis indirectas, después de pasar por una etapa de tejido calloso. Pero aún existen numerosas especies importantes del género que no han sido estudiadas desde el punto de vista biotecnológico, a pesar del potencial de estas técnicas en el uso, conservación y mejoramiento de las mismas. En este trabajo se establecieron protocolos para la propagación masiva in vitro de $\mathrm{A}$. $\mathrm{Cu}$ preata, A. karwinskii, A. potatorum, A. difformis y $A$. obscura; las tres primeras se utilizan para producir mezcal en los Estados de Guerrero y Oaxaca, y las dos últimas son ornamentales.

\section{MATERIALES Y MÉTODOS}

Las semillas de $A$. cupreata Trel. \& Berger, $A$. difformis Berger, $A$. karwinskii Zucc., A. obscura Schiede y $A$. potatorum Zucc. se desinfectaron mediante tres lavados por 10 min con detergente líquido (Dermoclean ${ }^{\circledR}$ ) a 1 $\%$ en agua corriente, luego un lavado con etanol a $70 \%$ durante $45 \mathrm{~s}$, y después se sumergieron por 25 min en una solución de blanqueador comercial (Cloralex $®$ ) a $15 \%$ $(\mathrm{v} / \mathrm{v})$. Finalmente se enjuagaron cuatro veces con agua destilada estéril bajo condiciones de asepsia, y se inocularon en el medio de cultivo.

El medio basal que se utilizó fue el MS (Murashige y Skoog, 1962), a pH 5.7 y con $8 \mathrm{~g} \mathrm{~L}^{-1}$ de agar (SigmaAldrich) como gelificante. Los cultivos se mantuvieron a $25 \pm 2{ }^{\circ} \mathrm{C}$ bajo luz continua $\left(54 \mu \mathrm{mol} \mathrm{m} \mathrm{m}^{-2} \mathrm{~s}^{-1}\right)$ por 30 a 45 $\mathrm{d}$, hasta tener plántulas de 3 a $6 \mathrm{~cm}$ de altura. Este medio basal y condiciones de incubación se aplicaron en todos los experimentos posteriores. A partir de estas plántulas se tomaron los explantes que se utilizaron en los experimentos de multiplicación in vitro. Para esto, se eliminaron sus hojas y raíces, y la porción restante que contenía los tejidos meristemáticos se inoculó en medio basal adicionado con diversos tipos y concentraciones de citocininas con el fin de determinar el tratamiento hormonal más eficiente para estimular la generación de brotes múltiples en los explantes.

Las citocininas probadas fueron: 6-bencilaminopurina o benciladenina (BA), 6- $\gamma, \gamma$-dimetilalilaminopurina (2iP), cinetina (Cin), tidiazurón (TDZ) y $\left[\mathrm{N}^{6}\right.$-(metahidroxibencil)adenina] o metatopolina (MT) (todas de la marca PhytoTechnology Laboratories), en las concentraciones que se muestran en el Cuadro 1. Los cultivos se mantuvieron en las condiciones antes descritas y a los 90 d se registró el número de brotes generados en cada explante. Se utilizó un mínimo de ocho explantes de cada especie por tratamiento. Los datos se sometieron a análisis de varianza y comparación de medias con prueba de Tukey $(\mathrm{P} \leq 0.05)$.

Los brotes generados en los medios de multiplicación con citocininas se separaron del explante original y se transfirieron a medio basal sin reguladores del crecimiento, para promover la formación del sistema radical. A los 30 d de incubación se registró el porcentaje de brotes enraizados. Finalmente, a los recipientes con brotes enraizados se les eliminó el sello y se les aflojó la tapa para promover la adaptación paulatina de los brotes a las condiciones de humedad del medio externo. Después de $15 \mathrm{~d}$ en estas condiciones, los brotes se sacaron del medio de cultivo, se lavaron con agua corriente para eliminar los restos del mismo, se sembraron en una mezcla 1:1 de suelo comercial para macetas y arena, y se transfirieron al invernadero.

La supervivencia en invernadero de las plantas generadas in vitro se determinó entre los 30 y $45 \mathrm{~d}$. Se consideró que la adaptación al suelo fue exitosa cuando la planta dio señales de reiniciar su crecimiento. Para la etapa de enraizamiento se evaluaron al menos 10 lotes de 10 brotes cada uno por especie, mientras que para la adaptación y transferencia a suelo se usaron 10 lotes de seis plántulas. En ambos casos los datos se analizaron estadísticamente de la manera antes descrita, para determinar si hubo diferencias entre especies en estas etapas.

\section{RESULTADOS Y DISCUSIÓN}

El porcentaje de contaminación de las semillas fue inferior a $20 \%$. Los porcentajes de germinación in vitro fueron de 68, 66, 63, 100 y $60 \%$ para Agave cupreata, A. difformis, A. karwinskii, A. obscura y A. potatorum, respectivamente. De los 30 a los 45 d se tenían ya plántulas de 3 a $6 \mathrm{~cm}$, las cuales sirvieron como fuente de explantes para los experimentos siguientes.

Los explantes basales provenientes de las plántulas germinadas in vitro generaron brotes múltiples en la mayoría de tratamientos con citocininas. A. cupreata generó brotes en todos los tratamientos con BA, 2iP, Cin y TDZ (Figura 1a), pero no respondió a la MT. Los mejores tratamientos fueron $1.5 \mathrm{mg} \mathrm{L}^{-1}$ de $\mathrm{BA}$, con un promedio de 10.5 brotes por explante; y $2.0 \mathrm{mg} \mathrm{L}^{-1}$ de $2 \mathrm{iP}$, con 10.0 brotes por explante (Cuadro 1). Como los brotes más 
vigorosos se obtuvieron con BA, ésta se considera la citocinina más recomendable para esta especie.

Para A. difformis el mejor tratamiento fue $0.2 \mathrm{mg} \mathrm{L}^{-1}$ de TDZ, con un promedio de 8.5 brotes por explante, aun cuando $2 \mathrm{iP}$ a $2 \mathrm{mg} \mathrm{L}^{-1}$ y MT a $0.5 \mathrm{mg} \mathrm{L}^{-1}$ generaron resultados estadísticamente similares (Figura 1b y Cuadro 1). Esta especie generó brotes con las cinco citocininas, pero los tratamientos con BA indujeron $30 \%$ de brotes hiperhidratados que fueron incapaces de enraizar y sobrevivir a la transferencia a suelo. Es decir, la BA no es una citocinina recomendable para esta especie.

En $A$. karwinskii se observó respuesta muy pobre a la Cin y a la MT, mientras que con BA los resultados fueron más satisfactorios, en particular con la concentración de 1 $\mathrm{mg} \mathrm{L}^{-1}$ que dio un promedio de 6.1 brotes por explante; algunos tratamientos con $2 \mathrm{iP}$ indujeron valores inferiores, pero estadísticamente similares a este tratamiento. Además, el vigor de los brotes generados con BA fue mayor que con las otras citocininas (Figura 1c y Cuadro 1).

La especie $A$. obscura produjo el mayor número de brotes por explante con el tratamiento con $0.2 \mathrm{mg} \mathrm{L}^{-1} \mathrm{de}$ TDZ, con un promedio de 11 brotes. Los tratamientos con $0.1 \mathrm{mg} \mathrm{L}^{-1}$ de TDZ y 0.5 y $2.0 \mathrm{mg} \mathrm{L}^{-1}$ de MT generaron resultados estadísticamente similares (Figura 1d y Cuadro 1). También en esta especie se observó una respuesta positiva a todas las citocininas.
El tratamiento con $3.0 \mathrm{mg} \mathrm{L}^{-1}$ de Cin propició el mayor número de brotes por explante en $A$. potatorum, con un promedio de 6.9 similar, al promedio obtenido con 1.5 $\mathrm{mg} \mathrm{L}^{-1}$ de $2 \mathrm{iP}$ (Figura 1e y Cuadro 1). Esta especie dio respuesta nula al TDZ en todas las concentraciones, y la MT generó una cantidad escasa de brotes y todos hiperhidratados.

Los resultados confirman que cada especie responde de manera diferente a los reguladores del crecimiento suministrados in vitro, por lo cual resulta indispensable el desarrollo de protocolos de propagación particulares para cada una de ellas. Esto coincide con lo observado en cactáceas (Hubstenberger et al., 1992). Entre las cinco citocininas, la única que indujo brotes en todas las especies y concentraciones fue la BA; esta hormona y el $2 \mathrm{iP}$ dieron las respuestas más uniformes en las especies aquí trabajadas. Dado que la concentración más alta de citocinina que se usó produjo menor cantidad de brotes que algunos tratamientos intermedios, puede inferirse que el nivel óptimo se encuentra dentro del rango probado. Las citocininas Cin, TDZ y MT generaron resultados heterogéneos, pues fueron eficientes en algunas especies y en otras no tuvieron efecto.

En todos los estudios consultados acerca de la propagación in vitro de especies de Agave se utilizaron BA, 2iP o Cin, solas o combinadas con auxinas.

Cuadro 1. Efecto del tipo y concentración de citocininas en la generación de brotes a partir de meristemos basales en cinco especies de Agave, a los 90 d de incubación.

\begin{tabular}{|c|c|c|c|c|c|c|c|c|c|}
\hline \multicolumn{5}{|c|}{ Citocinina $\left(\mathrm{mg} \mathrm{L}^{-1}\right)$} & \multicolumn{5}{|c|}{ Brotes por explante } \\
\hline BA & $2 \mathrm{iP}$ & Cin & TDZ & MT & A. cupreata & A. difformis & A. karwinskii & A. obscura & A. potatorum \\
\hline 0.5 & - & - & - & - & 2.4 defghi & $1.6 \mathrm{efg}$ & $1.0 \mathrm{hi}$ & 3.1 bcde & $2.1 \mathrm{de}$ \\
\hline 1.0 & - & - & - & - & $6.9 \mathrm{bcd}$ & 6.4 abcd & $6.1 \mathrm{a}$ & 4.7 cde & 5.0 abcd \\
\hline 1.5 & - & - & - & - & $10.5 \mathrm{a}$ & 3.6 cdefg & 2.4 cdef & $2.2 \mathrm{def}$ & 3.4 abcde \\
\hline 2.0 & - & - & - & - & $8.5 \mathrm{abc}$ & 3.1 defg & $1.9 \mathrm{defg}$ & $1.1 \mathrm{ghi}$ & $2.0 \mathrm{bcd}$ \\
\hline 3.0 & - & - & - & - & $1.6 \mathrm{ghi}$ & $2.1 \mathrm{efg}$ & $1.2 \mathrm{fgh}$ & $1.5 \mathrm{efgh}$ & $2.4 \mathrm{abcd}$ \\
\hline- & 0.5 & - & - & - & $2.5 \mathrm{defgh}$ & $0.1 \mathrm{e}$ & 3.9 abcd & $0.1 \mathrm{i}$ & $2.0 \mathrm{de}$ \\
\hline- & 1.0 & - & - & - & $3.2 \mathrm{bcd}$ & $2.0 \mathrm{efg}$ & $2.6 \mathrm{cdef}$ & $1.4 \mathrm{efgh}$ & 2.9 bcde \\
\hline- & 1.5 & - & - & - & $5.1 \mathrm{bcd}$ & $4.0 \mathrm{cdef}$ & 3.4 abcde & $6.6 \mathrm{bcd}$ & $6.4 \mathrm{ab}$ \\
\hline- & 2.0 & - & - & - & $10.0 \mathrm{ab}$ & $7.9 \mathrm{ab}$ & $4.6 \mathrm{ab}$ & $4.1 \mathrm{cdef}$ & $5.7 a b c$ \\
\hline - & 3.0 & - & - & - & 4.7 bcde & $1.9 \mathrm{efg}$ & $0.0 \mathrm{i}$ & 2.2 bcde & 2.9 bcde \\
\hline- & - & 1.0 & - & - & $3.1 \mathrm{cdfgh}$ & $0.6 \mathrm{fg}$ & $0.0 \mathrm{i}$ & $4.2 \mathrm{cde}$ & $1.0 \mathrm{~d}$ \\
\hline- & - & 1.5 & - & - & 3.2 cdefg & $0.2 \mathrm{fg}$ & $0.0 \mathrm{i}$ & $2.1 \mathrm{defg}$ & $1.6 \mathrm{de}$ \\
\hline - & - & 2.0 & - & - & $4.0 \mathrm{cdef}$ & $0.6 \mathrm{fg}$ & $0.0 \mathrm{i}$ & 5.4 bcde & $1.4 \mathrm{e}$ \\
\hline- & - & 3.0 & - & - & 4.7 bcde & $0.4 \mathrm{fg}$ & 3.9 abcd & $7.6 \mathrm{abcd}$ & $6.9 \mathrm{a}$ \\
\hline- & - & - & 0.1 & - & 1.7 efghi & 5.0 abcde & $1.4 \mathrm{efgh}$ & $8.6 \mathrm{ab}$ & $0.0 \mathrm{e}$ \\
\hline- & - & - & 0.2 & - & 8.4 abc & $8.5 \mathrm{a}$ & 3.1 abcdef & $11.0 \mathrm{a}$ & $0.0 \mathrm{e}$ \\
\hline- & - & - & 0.3 & - & $7.5 \mathrm{abcd}$ & 4.6 bcde & $2.7 \mathrm{cdef}$ & 5.1 bcde & $0.0 \mathrm{e}$ \\
\hline- & - & - & 0.4 & - & 2.6 defgh & $7.0 \mathrm{abc}$ & $1.0 \mathrm{hi}$ & 5.6 bcde & $0.0 \mathrm{e}$ \\
\hline- & - & - & - & 0.5 & $0.0 \mathrm{i}$ & $7.2 \mathrm{abc}$ & 2.2 cdefg & $7.2 \mathrm{abcd}$ & $0.0 \mathrm{e}$ \\
\hline- & - & - & - & 1.0 & $0.0 \mathrm{i}$ & $0.0 \mathrm{~g}$ & $0.0 \mathrm{i}$ & 4.7 cde & $0.7 \mathrm{e}$ \\
\hline- & - & - & - & 1.5 & $0.2 \mathrm{hi}$ & $1.6 \mathrm{efg}$ & $0.0 \mathrm{i}$ & $2.2 \mathrm{def}$ & $0.4 \mathrm{e}$ \\
\hline- & - & - & - & 2.0 & $0.0 \mathrm{i}$ & $0.1 \mathrm{~g}$ & $0.0 \mathrm{i}$ & $7.9 \mathrm{abc}$ & $0.0 \mathrm{e}$ \\
\hline
\end{tabular}

$\mathrm{BA}=$ Benciladenina; 2 i $\mathrm{P}=$ Dimetilalilaminopurina; Cin $=$ Cinetina; TDZ = Tidiazurón; MT = Matatopolina. Medias con letras iguales dentro de la misma columna no son estadísticamente diferentes (Tukey, 0.05). 
Los resultados muestran que si bien la MT no parece ser eficiente en las especies y concentraciones probadas, el TDZ podría ser una alternativa atractiva al uso de las otras citocininas para algunas especies de Agave. Esta ci- tocinina sintética, aplicada con frecuencia en especies leñosas (Huetteman y Preece, 1993), resultó ser la más eficiente para la proliferación in vitro de $A$. difformis y $A$. obscura.
A

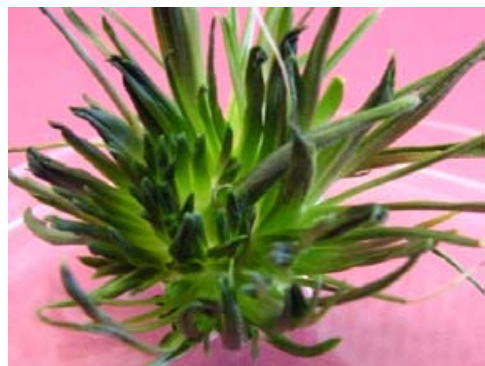

B

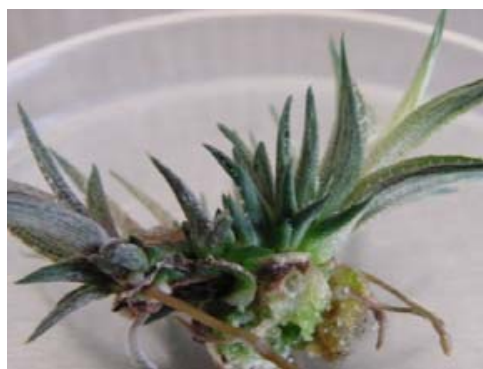

C

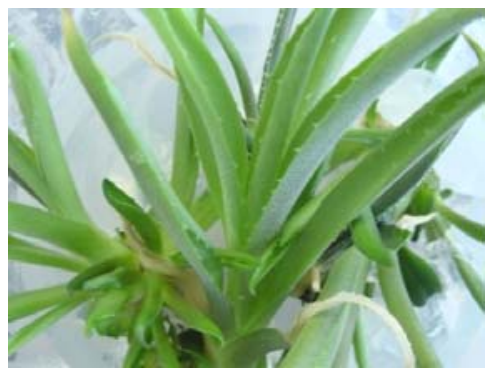

D

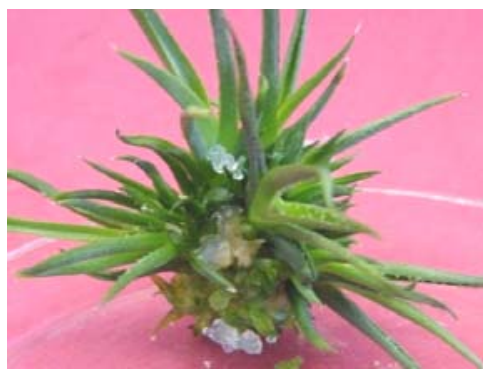

$\mathbf{E}$

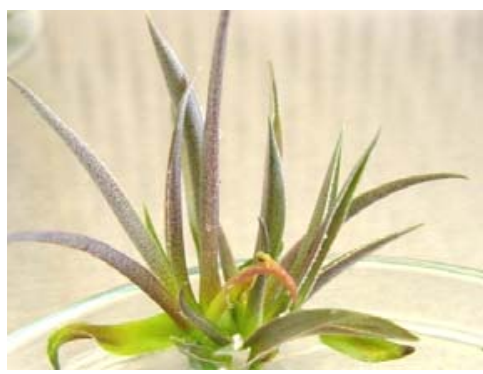

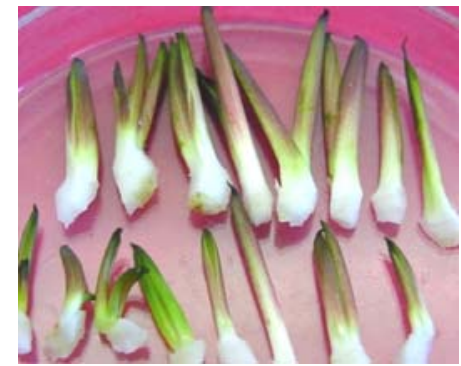
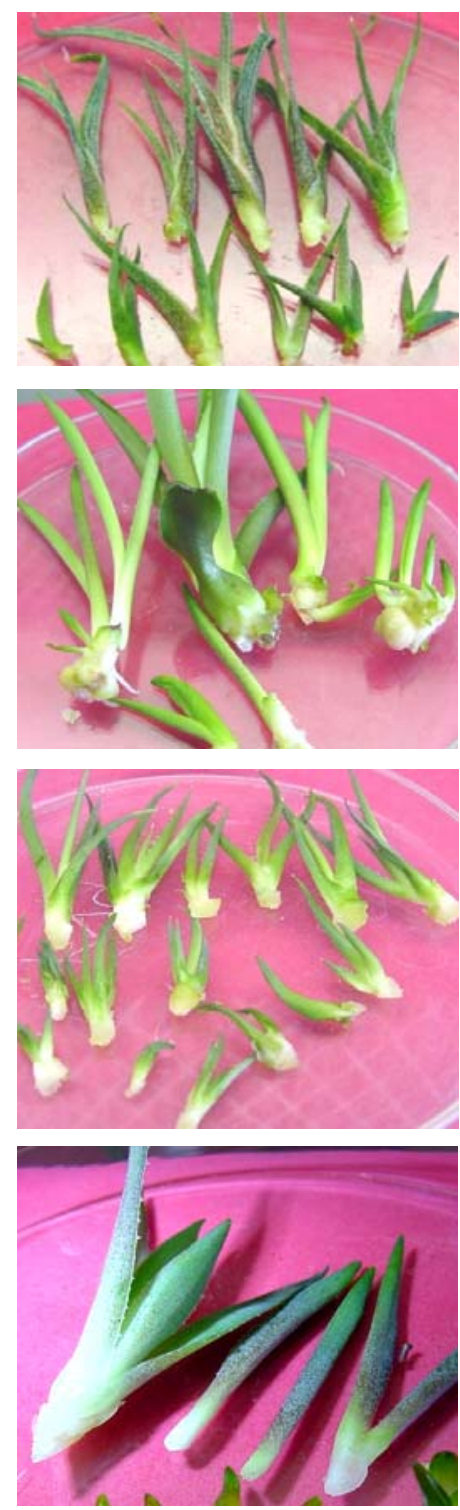
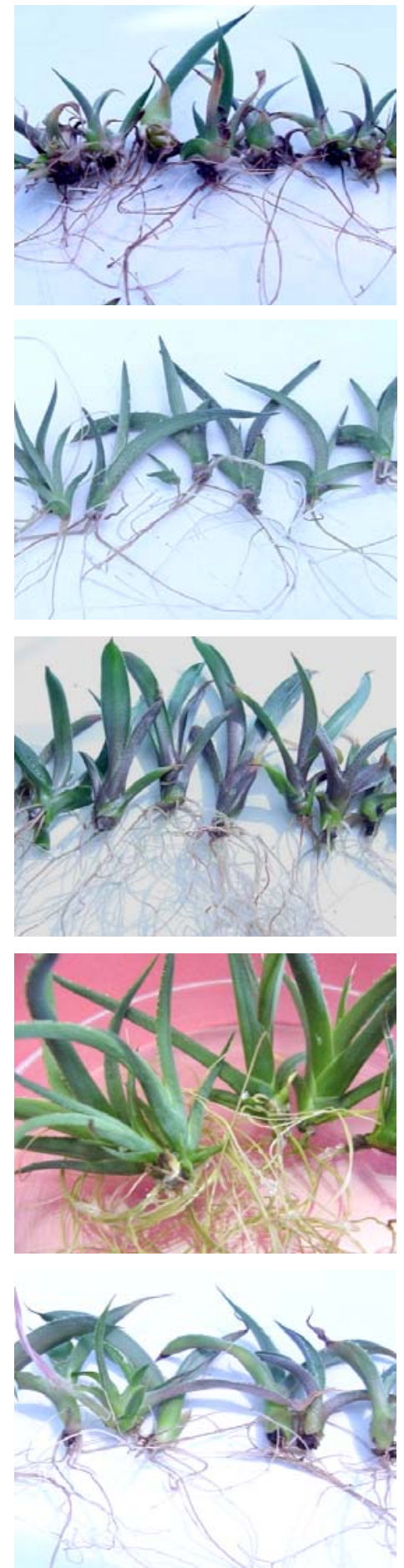

Figura 1. Generación de brotes en explantes basales cultivados en medio con citocininas (izquierda), brotes separados del explante original antes de su transferencia a medio de enraizamiento (centro) y brotes ya enraizados in vitro y listos para su transferencia a suelo (derecha). A) Agave cupreata; B) A. difformis; C) A. karwinskii; D) A. obscura; y E) A. potatorum. 
En cuanto a la eficiencia de los protocolos, Nikam (1997) reportó la generación de 5.7 brotes por explante en un tratamiento con $0.5 \mathrm{mg} \mathrm{L}^{-1}$ de Cin en $A$. sisalana. Santacruz-Ruvalcaba et al. (1999) obtuvieron 22 brotes por explante con $3 \mathrm{mg} \mathrm{L}^{-1}$ de BA, mientras que MartínezPalacios et al. (2003) reportaron 2.2 brotes por explante en $A$. victoria-reginae cultivado con $1 \mathrm{mg} \mathrm{L}^{-1}$ de BA. Estos investigadores también usaron meristemos similares como explantes, y sus resultados confirman la respuesta heterogénea que ocurre entre las especies de Agave, como se observó en este trabajo. Valenzuela-Sánchez et al. (2006) reportaron promedios de hasta 19.5 brotes por explante en $A$. tequiliana con un sistema de organogénesis indirecta, sistema de regeneración que al igual que la embriogénesis somática puede ser más eficiente que la formación de brotes a partir de tejidos meristemáticos. Sin embargo, el pasar por una fase de tejido calloso los hace proclives a variación somaclonal (Oliveira et al., 1995), lo cual es indeseable cuando se busca propagar masivamente para conservar el acervo genético de los materiales originales. Por ello en este trabajo se seleccionaron tratamientos con bajos niveles de citocininas y sin auxinas, lo que permitió generar brotes sin la formación de tejido calloso en los explantes.

El enraizamiento de los brotes generados se logró en medio basal sin reguladores del crecimiento, con eficiencias de 80 a $100 \%$ (Cuadro 2). Aparentemente, las citocininas usadas para generar brotes no afectaron su capacidad de enraizamiento. Sin embargo, en $A$. obscura los brotes generados con BA y transferidos a medio sin reguladores del crecimiento para su enraizamiento, siguieron generando más brotes al mismo tiempo que producían raíz. Esto parece indicar que en esta especie la BA tiene una fuerte actividad residual, la cual no afecta la capacidad de enraizamiento. En todos los casos los sistemas radicales generados en el medio sin reguladores del crecimiento fueron vigorosos (Figura 1).

Cuadro 2. Enraizamiento en medio MS basal de los brotes obtenidos de cinco especies de Agave, y supervivencia de plántulas en suelo.

\begin{tabular}{lcc}
\hline Especie & $\begin{array}{c}\text { Enraizamiento } \\
(\%)\end{array}$ & $\begin{array}{c}\text { Sobrevivencia en } \\
\text { suelo }^{\dagger \dagger}(\%)\end{array}$ \\
\hline Agave cupreata & $93 \mathrm{ab}$ & $53 \mathrm{~b}$ \\
Agave difformis & $100 \mathrm{a}$ & $73 \mathrm{ab}$ \\
Agave karwiskii & $80 \mathrm{~b}$ & $60 \mathrm{ab}$ \\
Agave obscura & $100 \mathrm{a}$ & $100 \mathrm{a}$ \\
Agave potatorum & $87 \mathrm{ab}$ & $73 \mathrm{ab}$ \\
\hline
\end{tabular}

Medias con letras iguales en una misma columna no son estadísticamente diferentes (Tukey, 0.05).

${ }^{\dagger}$ Medida a los $30 \mathrm{~d}$ de incubación en medio sin reguladores del crecimiento. ${ }^{\dagger \dagger}$ Medida entre 30 y $45 \mathrm{~d}$ después de la transferencia ex vitro.
Resultados similares se han reportado para $A$. arizonica (Powers y Backhaus, 1989), A. parrasana (SantacruzRuvalcaba et al., 1999) у A. victoria-reginae (MartínezPalacios et al., 2003), que mostraron altas tasas de enraizamiento sin necesidad de auxinas. Solamente en $A$. angustifolia se ha recomendado el uso de ácido indolbutírico (AIB) para inducir el enraizamiento in vitro (Enríquezdel-Valle et al., 2005), y en $A$. salmiana la auxina recomendada para el enraizamiento es el ácido indolacético (AIA) (Silos-Espino et al., 2007). En cuanto a la supervivencia en invernadero de las plantas generadas in vitro, varió de 53 a $100 \%$ (Figura 2 y Cuadro 2). Los valores más bajos de supervivencia tal vez se podrían incrementar con otros sustratos, ya que los requerimientos de las plantas en este sentido pueden variar entre especies en función de las condiciones del hábitat natural de cada una. Todas las plantas que sobrevivieron al proceso de adaptación al medio externo continúan vivas un año después, y muestran un crecimiento vigoroso ex vitro.

\section{CONCLUSIONES}

Este trabajo demostró que es posible propagar in vitro de manera eficiente a las especies Agave cupreata, A. difformis, A. karwinskii, A. obscura y A. potatorum, para las que no existían antecedentes en este sentido. Los protocolos desarrollados generaron entre $6.1 \mathrm{y} 11$ brotes por explante en promedio, según la especie; estas tasas de propagación se lograron en el mejor tratamiento con citocininas, y después de 90 d de incubación. Estos protocolos tienen potencial para generar entre 1412 y 14641 nuevas plantas a partir de un solo explante, en el lapso de un año (cuatro ciclos de cultivo). También se encontró que el tidiazurón (TDZ) puede ser una alternativa eficiente para la generación de brotes en algunas especies del género, hecho no reportado previamente en la literatura. Los métodos desarrollados pueden aplicarse para la generación masiva de plantas para su aprovechamiento, y para disminuir así las presiones que la sobreexplotación ejerce sobre las poblaciones silvestres.

\section{AGRADECIMIENTOS}

A la Universidad Autónoma de Aguascalientes por el apoyo financiero brindado al proyecto (PIBT-06-3) y al Consejo Nacional de Ciencia y Tecnología por la beca otorgada a MSDR. 


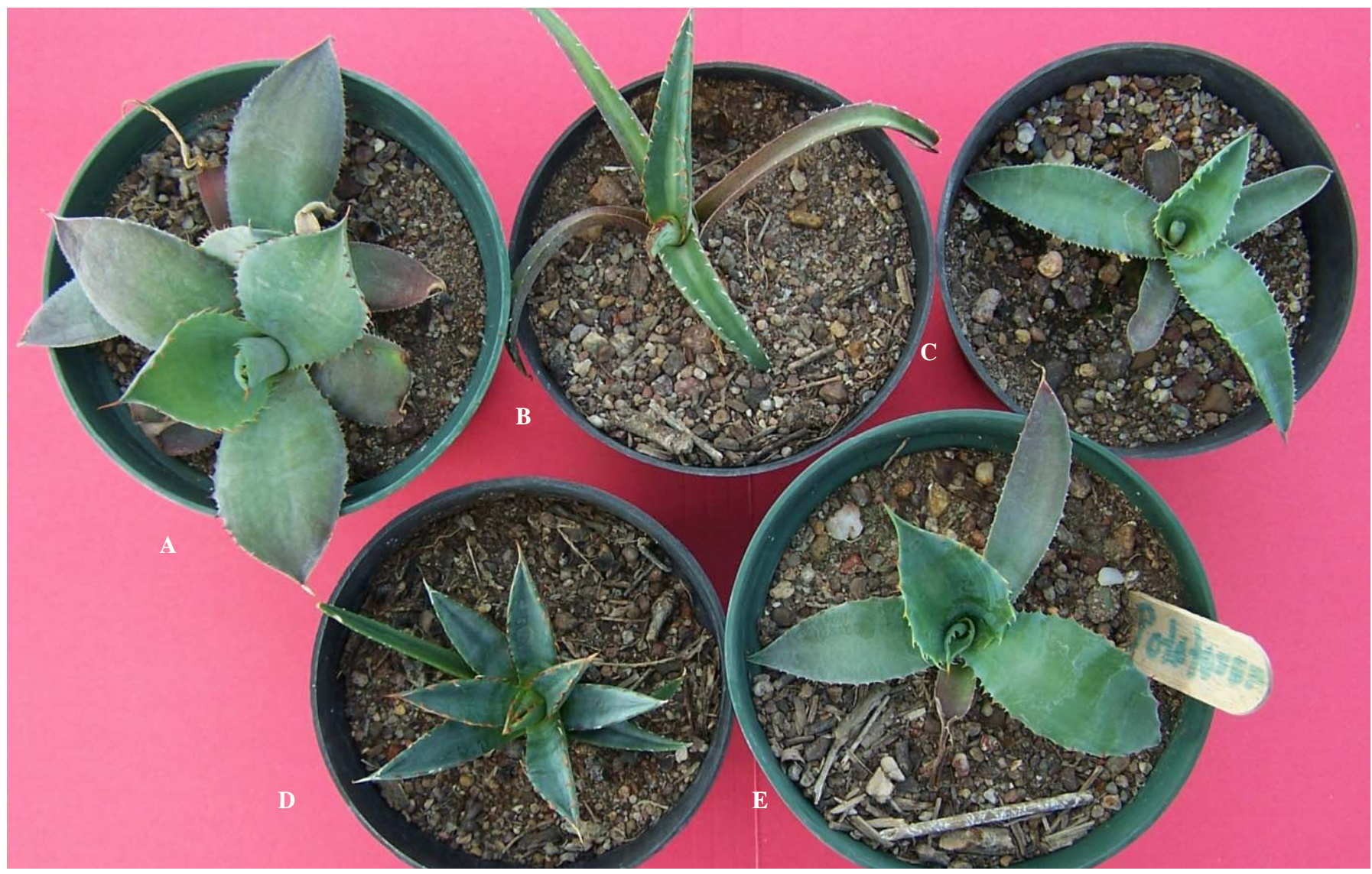

Figura 2. Plantas generadas in vitro creciendo en invernadero, a cuatro meses de su transferencia a suelo. A) Agave cupreata; B) A. difformis; C) A. karwinskii; D) A. obscura; y E) A. potatorum.

\section{BIBLIOGRAFÍA}

Binh L T, L T Muoi, H T K Oanh, T D Thang, D T Phong (1990) Rapid propagation of agave by in vitro tissue culture. Plant Cell Tiss. Org. Cult. 23:67-70.

Enríquez-del-Valle J R , G Carrillo-Castañeda, J L Rodríguez-de-laO (2005) Sales inorgánicas y ácido indolbutírico en el enraizado in vitro de brotes de Agave angustifolia. Rev. Fitotec. Mex. 28:175-178.

García-Mendoza A (1995) Riqueza y endemismos de la familia Agavaceae en México. In: Conservación de Plantas en Peligro de Extinción: Diferentes Enfoques. E Linares, P Dávila, F Chiang, R Bye, T Elías (eds). UNAM. México, D.F. pp:51-75.

Hazra K S, S Das, K A Das (2002) Sisal plant regeneration via organogenesis. Plant Cell Tiss. Org. Cult. 70:235-240.

Hubstenberger J F, P W Clayton, G C Phillips (1992) Micropropagation of Cacti (Cactaceae). In: Biotechnology in Agriculture and Forestry, Vol. 20. High-Tech and Micropropagation IV. Y P S Bajaj (ed). Springer-Verlag. Berlin. pp:49-68.

Huetteman C A, J E Preece (1993) Thidiazuron: a potent cytokinin for woody plant tissue culture. Plant Cell Tiss. Org. Cult. 33:105-119.

Martínez-Palacios A, M P Ortega-Larrocea, M V Chávez, R Bye (2003) Somatic embryogenesis and organogenesis of Agave victoriae- reginae: Considerations for its conservation. Plant Cell Tiss. Org. Cult. 74:135-142.
Murashige T, F Skoog (1962) A revised medium for rapid growth and bioassays with tobacco tissue cultures. Physiol. Plant. 15:473-497.

Nikam D T (1997) High frequency shoot regeneration in Agave sisalana. Plant Cell Tiss. Org. Cult. 51:225-228.

Oliveira S A, M F P S Machado, A J Prioli (1995) In vitro propagation of Cereus peruvianus Mill (Cactaceae). In Vitro Cell. Dev. Biol. Plant 31:47-50.

Powers D E, R A Backhaus (1989) In vitro propagation of Agave arizonica Gentry \& Weber. Plant Cell Tiss. Org. Cult. 16:5760.

Robert M L, J L Herrera, F Contreras, K N Scorer (1987) In vitro propagation of Agave fourcroydes. Plant Cell Tiss. Org. Cult. 8:37-48.

Santacruz-Ruvalcaba F, H Gutiérrez-Pulido, B Rodríguez-Garay (1999) Efficient in vitro propagation of Agave parrasana Berger. Plant Cell Tiss. Org. Cult. 56:163-167.

Silos-Espino H, N González-Cortés, A Carrillo-López, F GuevaraLara, ME Valverde-González, O Paredes-López (2007) Chemical composition and in vitro propagation of Agave salmiana "Gentry". J. Hort. Sci. Biotechnol. 82:355-359.

Valenzuela-Sánchez $\mathbf{K} \quad \mathbf{K}, \quad \mathbf{R} \quad \mathbf{E}$ Juárez-Hernández, A CruzHernández, V Olalde-Portugal, M E Valverde, O ParedesLópez (2006) Plant regeneration of Agave tequilana by indirect organogenesis. In Vitro Cell. Dev. Biol. Plant 42:336340 . 